\title{
Clinical outcome and prognostic factors for patients treated within the context of a phase I study: the Royal Marsden Hospital
} experience

\author{
H-T Arkenau*, I,2, D Olmos', ${ }^{1,2}$, JE Ang', J de Bono', I Judson' and S Kaye*,I \\ 'Drug Development Unit, Royal Marsden Hospital and Institute of Cancer Research, Downs Road, Sutton SM2 5PT, UK
}

The main aim of phase I trials is to evaluate the tolerability and pharmacology of a new compound. However, investigating the potential for clinical benefit is also a key objective. Our phase I trial portfolio incorporates a range of new drugs, including molecular targeted agents, sometimes given together with cytotoxic agents. We performed this analysis of response rate, progression-free (PFS) and overall survival (OS) to assess the extent of clinical benefit rate (CBR: partial response (PR) + stable disease (SD)) derived from current trials. We analysed 212 consecutive patients who were treated in 29 phase I studies, from January 2005 to June 2006 . All patients had progression of disease prior to study entry. The median age was 58 years (range: 18-86) with a male/female ratio of 2 : I. A total of 148 patients (70\%) were treated in 'first in human trials' involving biological agents ( 32 patients) or new cytotoxic compounds ( 16 patients) alone, and 64 patients (30\%) received chemotherapy-based regimens with or without biological agents. After a median follow-up time of 34 weeks, the median PFS and OS were II and 43 weeks, respectively. The CBR was 53\% (9\% PR and $44 \%$ SD) after the first tumour evaluation after two cycles (between weeks 6 and 8 ) and has been maintained at 36 and $26 \%$ at 3 and 6 months, respectively. Treatment related deaths occurred in $0.47 \%$ of our patients and treatment had to be withdrawn in $11.8 \%$ of patients due to toxicity. A multivariate analysis (MVA) of 13 factors indicated that low albumin $\left(<35 \mathrm{gl}^{-1}\right)$, lactate dehydrogenase $>$ upper normal limit and $>2$ sites of metastasis were independent negative prognostic factors for OS. A risk score based on the MVA revealed that patients with a score of 2-3 had a significantly shorter OS compared to patients with a score of 0-I (24.9 weeks, 95\% Cl 19.5-30.2 vs 74.I weeks, 95\% Cl 53.2-96.2). This analysis shows that a significant number of patients who develop disease progression while receiving standard therapy derived benefit from participation in phase I trials. Risk scoring based on objective clinical parameters indicated that patients with a high score had a significantly shorter OS, and this may help in the process of patient selection for phase I trial entry.

British Journal of Cancer (2008) 98, 1029-1033. doi:I0.1038/sj.bjc.66042I8 www.bjcancer.com

Published online 18 March 2008

(c) 2008 Cancer Research UK

Keywords: phase I trial; outcome; survival; prognostic factors

Patients with advanced cancers most commonly face the dilemma of having no available standard treatment option. A minority of patients with good performance status (PS) and adequate organ function are sometimes offered treatment within the context of a phase I trial. Phase I trials are designed primarily to evaluate the tolerability and toxicity profile of new therapies. The generally accepted inclusion and exclusion criteria for these trials include adequate organ function and reasonable PS in order to ensure safety and avoid unnecessary toxicity. Another important entry criterion is life expectancy predicted to be more than 3 months, and this is notoriously difficult to predict. More accurate selection criteria or even prognostic scores for patients who will potentially benefit from a clinical phase I trial may therefore be helpful.

\footnotetext{
*Correspondence: Professor S Kaye; E-mail: stan.kaye@icr.ac.uk and

Dr H-T Arkenau; E-mail: hendrik-tobias.arkenau@icr.ac.uk

2 These authors contributed equally to this work.

Received 9 November 2007; revised 19 December 2007; accepted 7 January 2008; published online 18 March 2008
}

So far, there have been few studies exploring factors associated with clinical outcome, toxicity and prognosis in this context. Multivariate analyses (MVAs) have revealed that factors such as poor PS, high lactate dehydrogenase (LDH), low albumin, and certain chemotherapy regimens could be negative prognostic factors for survival. However, one of the drawbacks of these studies has been that most analyses have been performed over a long period of time, some of them over 10 years. Moreover, most of these studies focused on the 'classical cytotoxic drug development era' and not on the newer generations of molecularly targeted or biological agents (Yamamoto et al, 1999; Han et al, 2003; Penel et al, 2008).

Biological agents target a certain molecular structure or pathway relevant for cancer growth. Broadly speaking, the mechanism of action usually results in a cytostatic rather than cytotoxic effect, resulting in lower toxicity to normal tissue.

We performed this retrospective analysis in all patients who took part in phase I trials at the Drug Development Unit, Royal Marsden Hospital, over an 18-month period, from January 2005 to June 2006. During this period, the majority of our trials involved 
biological agents. Clinical parameters, blood tests (biochemistry and full blood count (FBC)), tumour type, toxicity and type of treatment were included in our univariate and MVAs. The main aim of this study was to analyse the clinical outcome for our large patient population treated in phase I trials. Secondly, we were interested in the impact of the type of phase I trial on clinical outcome. Our third aim was to analyse factors that could guide us in the development of an improved patient selection process for phase I trials.

\section{PATIENTS AND METHODS}

\section{Patient characteristics}

We analysed the outcome of 212 consecutive patients who were treated from January 2005 to June 2006 in 29 phase I trials at the Drug Development Unit, Royal Marsden Hospital, Sutton, UK. All patients had to have objective evidence of progressive disease prior to trial entry. The median age was 58 years (range: $18-86$ ) with a male/female ratio of 2:1 (142 male and 70 female). Overall, the patients had a median of two cycles of prior systemic therapy (range $0-8$ ). The Eastern Cooperative Oncology Group (ECOG) PS was 0,1 and 2 in 28,66 and $6 \%$ of patients, respectively. A total of $33.5 \%$ of the patients had urological tumours, $15.6 \%$ had breast and gynaecological tumours, $14.2 \%$ had lung, mesothelioma and head and neck tumours, $12.3 \%$ had sarcoma, $12.3 \%$ had gastrointestinal tumours, $6.1 \%$ had melanoma, and $6.1 \%$ others. Of the patients with urological tumours, 37 of 54 had prostate cancer previously untreated with chemotherapy. Sixty-four per cent had $\leqslant 2$ sites of metastasis and $36 \%$ had $\geqslant 2$ sites of metastasis (median 2, range: $0-8$ ). The most common sites of metastasis were lung (41\%), bone (29\%) and liver (27\%). Baseline biochemistry showed decreased albumin levels in $57 \%$ of the patients (albumin $<35 \mathrm{gl}^{-1}$ ) and LDH levels were above the upper normal limit (UNL: >192 IU) in 49\%. The FBC showed haemoglobin levels $<12 \mathrm{~g} \mathrm{dl}^{-1}$ in $41 \%$, a white cell count (WCC) $>10500 \mathrm{~mm}^{-3}$ in $11 \%$ and platelets $>400000 \mathrm{~mm}^{-3}$ in $24 \%$ of the patients (Table 1).

\section{Trial characteristics}

During the 18-month study period, all 212 consecutive patients were treated within one of 29 phase I trials. A total of 148 patients (70\%) were treated in 'first in human trials' involving biological agents (132 patients) or new cytotoxic compounds (16 patients) alone and 64 patients $(30 \%)$ received chemotherapy-based regimens with or without biological agents. According to the various protocols, the first tumour evaluation was performed before the third cycle, between weeks 6 and 8. Trial categories are summarised in Table 1.

Of our 29 trials, 19 trials have already been completed and phase II doses were recommended; 17 of the 19 trials reached maximumtolerated doses (MTDs). Three trials were closed early based on the sponsor's decision. Seven trials are still ongoing and four of them have reached MTDs. Overall, MTDs were defined for 21 of the 29 trials.

\section{Statistical consideration}

The SPSS Programme (Version 12.0, Chicago, IL, USA) was used for statistical analysis. The Kaplan-Meier method was used to estimate progression-free (PFS) and overall survival (OS) and the log-rank test was used to compare the survival curves (Kaplan and Meier, 1958). The Cox regression model has been applied for HR estimation and for MVA of prognostic factors for PFS and OS, using a backward selection approach (Cox, 1972). Fisher's exact test and the $\chi^{2}$ test for trend were used to compare proportions of
Table I Baseline patient and treatment characteristics

\begin{tabular}{|c|c|c|c|}
\hline \multirow{2}{*}{$\begin{array}{l}\text { Characteristics } \\
\text { Sex }\end{array}$} & \multirow[t]{2}{*}{ Median (range) } & \multicolumn{2}{|c|}{ Number \% } \\
\hline & & & \\
\hline Male & & 142 & 67 \\
\hline Female & & 70 & 33 \\
\hline Age & 58 years $(19-86)$ & & \\
\hline$<65$ years & & 147 & 69 \\
\hline$\geqslant 65$ years & & 65 & 31 \\
\hline Performance status & & 208 & \\
\hline ECOG 0 & & 58 & 28 \\
\hline ECOG I & & 137 & 66 \\
\hline ECOG 2 & & 13 & 6 \\
\hline Previous treatments & $2(0-8)$ & & \\
\hline $0-2$ previous systemic lines & & 110 & 52 \\
\hline$\geqslant 3$ previous systemic lines & & 102 & 48 \\
\hline Number of involved areas & $2(0-8)$ & & \\
\hline Only locoregional disease & & 14 & 7 \\
\hline I-2 metastatic sites/areas & & 121 & 57 \\
\hline$\geqslant 3$ metastatic sites/areas & & 77 & 36 \\
\hline Metastatic specific sites & & & \\
\hline Liver & & 57 & 27 \\
\hline Lung & & 86 & 41 \\
\hline Bone & & 62 & 29 \\
\hline Baseline albumin & $33 \mathrm{gl}^{-1}(18-44)$ & & \\
\hline$<35 \mathrm{gl}^{-1}$ & & 91 & 57 \\
\hline$\geqslant 35 \mathrm{gl}^{-1}$ & & 121 & 43 \\
\hline Baseline $L D H$ level & $190 \mathrm{IUdl}^{-1}(55-2024)$ & & \\
\hline Normal LDH & & 108 & 51 \\
\hline Elevated LDH & & 104 & 49 \\
\hline Baseline Haemoglobin level & $11.95 \mathrm{~g} \mathrm{dl}^{-1}(8.7-16.0)$ & & \\
\hline$<12 \mathrm{~g} \mathrm{dl}^{-1}$ & & 86 & 41 \\
\hline$\geqslant 12 \mathrm{~g} \mathrm{dl}^{-1}$ & & 126 & 59 \\
\hline Baseline WBC count & $\begin{array}{c}7150 \mathrm{~mm}^{-3}(2900- \\
21200)\end{array}$ & & \\
\hline$\leqslant 10500 \mathrm{~mm}^{-3}$ & & 188 & 89 \\
\hline$>10500 \mathrm{~mm}^{-3}$ & & 24 & 11 \\
\hline Baseline platelets count & $\begin{array}{c}284000 \mathrm{~mm}^{-3} \\
(108000-797000)\end{array}$ & & \\
\hline$\leqslant 400000 \mathrm{~mm}^{-3}$ & & 162 & 76 \\
\hline$>400000 \mathrm{~mm}^{-3}$ & & 50 & 24 \\
\hline Cancer group & & 208 & \\
\hline Urological tumours & & 71 & 34 \\
\hline Breast and gynaecological cancers & & 33 & 16 \\
\hline Gastrointestinal cancers & & 26 & 12 \\
\hline Sarcomas & & 26 & 12 \\
\hline Thoracic and head and neck tumours & & 30 & 14 \\
\hline Melanoma & & 13 & 6 \\
\hline Others & & 13 & 6 \\
\hline Trial categories & & & \\
\hline 'First in human drugs' & & 148 & 70 \\
\hline $\begin{array}{l}\text { Cytotoxic drug combinations (including } \\
\text { FDA approved drugs) }\end{array}$ & & 64 & 30 \\
\hline Trial categories by target & & & \\
\hline Growth factor receptor pathways & & 63 & 30 \\
\hline $\begin{array}{l}\text { Chromatin remodelling, DNA repair and } \\
\text { antisense }\end{array}$ & & 41 & 19 \\
\hline Anti-angiogenesis & & 38 & 18 \\
\hline Cell cycle and apoptosis & & 27 & 13 \\
\hline Vaccine and virus & & 16 & 7.5 \\
\hline New cytotoxic compounds & & 16 & 7.5 \\
\hline Hormone synthesis & & 8 & 4 \\
\hline Protein turnover & & 3 & I \\
\hline
\end{tabular}


response rate (RR). All $P$-values presented are two-sided. The cutoff date for the present analysis was the 31 May 2007.

\section{Outcome: response, PFS and OS}

Of the 212 patients, 202 (95\%) had disease evaluable by the acknowledged standard Response Evaluation Criteria in Solid Tumours (RECIST) and Prostate Specific Antigen Working Group criteria (PSAWG) were also used to determine progressive disease but not response in this specific setting (Bubley et al, 1999; Therasse et al, 2000). Overall, there has been a radiological proven partial response (PR) in 19 patients (9.4\%), stable disease (SD) in 88 patients $(44 \%)$ and progression of disease in 95 patients $(47 \%)$ of all patients, respectively. The clinical benefit rate (CBR: $\mathrm{PR}+\mathrm{SD}$ ) was $53 \%$ after the first tumour evaluation after two cycles of treatment (between weeks 6 and 8) and has been maintained at 36 and $26 \%$ at 3 and 6 months, respectively. Patients who received a chemotherapy-based regimen had a RR of $19.7 \%$ and patients who received a biological agent $3.6 \%(P=0.01)$. The median duration of treatment was 6.9 weeks (range: $0-60.1$ weeks) in patients who received a biological agent and 10.6 weeks (range: 0.1-64.4 weeks, $P=0.027$ ) in patients who received a chemotherapy-based regimen with or without a biological agent. The 30 - and

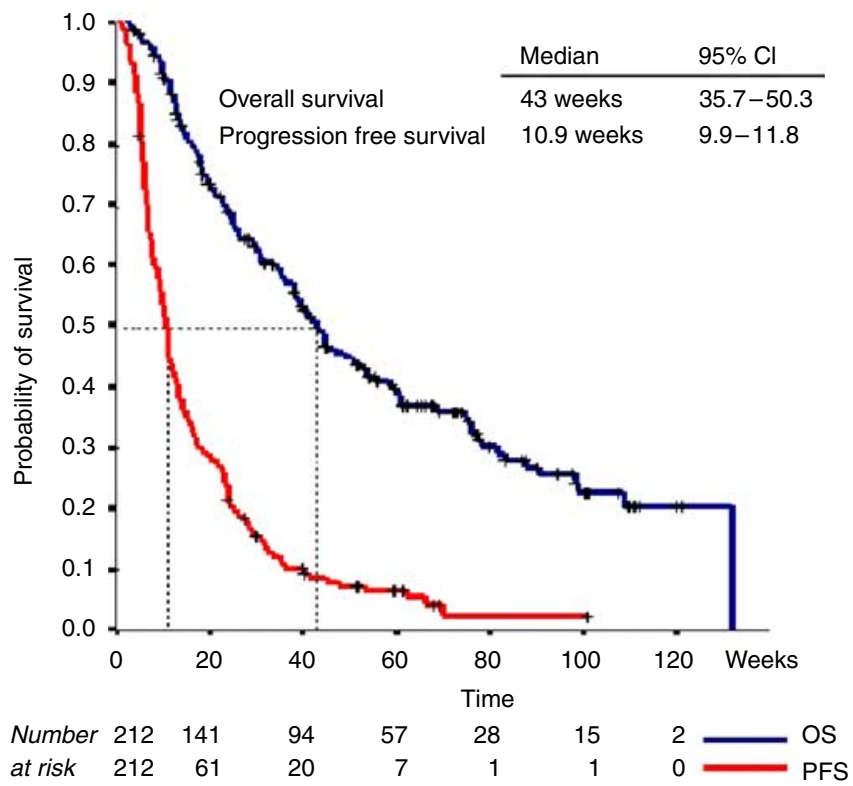

Figure I Kaplan-Meier Curves for progression-free (PFS) and overall survival (OS). 90-day mortality was $1.9 \%$ (4 out of 212 ) and $18.3 \%$ (39 out of 212 ), respectively. Treatment related mortality was $0.47 \%$ ( 1 out of 212 ) and $11.8 \%$ ( 25 out of 212 ) of the patients have been withdrawn from an ongoing study due to toxicity (Table 2).

After a median follow-up of 34 weeks (range: 2.7-131.9), the PFS was 11 weeks (95\% CI: 9.9-11.8) and the median OS 43 weeks (95\% CI: 3.8-50.3), respectively (Figure 1). Univariate analysis revealed that ECOG PS 2, >2 sites of metastasis, albumin $<35 \mathrm{~g} \mathrm{day}^{-1}$, LDH $>$ UNL, WCC $>10500 \mathrm{~mm}^{-3}$, haemoglobin $<12 \mathrm{~g} \mathrm{dl}^{-1}$, platelets $>400000 \mathrm{~mm}^{-3}$, among other factors, were highly significant negative prognosticators for OS. In the MVA, LDH $>$ UNL $(P=0.003)$, albumin $<35 \mathrm{~g} \mathrm{dl}^{-1}(P<0.001)$, and $>2$ sites of metastasis $(P=0.01)$ were significant negative prognosticators for OS (Table 3). Since our patient population included a number of chemonaive prostate cancer patients and our trial

Table 3 Overall survival and prognostic factor categories (log-rank test for univariate analysis and Cox regression for multivariate analysis)

\begin{tabular}{|c|c|c|c|c|}
\hline \multirow[b]{2}{*}{$(n=212)$} & \multirow[b]{2}{*}{$\begin{array}{l}\text { Median } \\
\text { (weeks) }\end{array}$} & \multirow[b]{2}{*}{$95 \% \mathrm{Cl}$} & \multicolumn{2}{|c|}{ Statistical analysis } \\
\hline & & & $\begin{array}{l}\text { Univariate } \\
\text { Log Rank }\end{array}$ & $\begin{array}{c}\text { Multivariate } \\
\text { Cox Reg }\end{array}$ \\
\hline Albumin $<35 \mathrm{gl}^{-1}$ & 26 & $18.6-33.4$ & $<0.0001$ & 0.007 \\
\hline Normal albumin & 74 & $54.3-95.1$ & & \\
\hline Elevated LDH & 34 & $24.3-44.0$ & 0.003 & 0.002 \\
\hline Normal LDH & 59 & $41.6-77.0$ & & \\
\hline WCC $>10500 \mathrm{~mm}^{-3}$ & 16 & $5.7-26.3$ & $<0.0001$ & 0.439 \\
\hline Normal WCC & 47 & $36.6-56.8$ & & \\
\hline $\mathrm{HGB}<12 \mathrm{gdl}^{-1}$ & 31 & $22.4-39.0$ & 0.0001 & 0.309 \\
\hline Normal HGB & 60 & $37.9-82.4$ & & \\
\hline PLT $>400000 \mathrm{~mm}^{-3}$ & 23 & $8.3-37.7$ & 0.0035 & 0.394 \\
\hline Normal PLT & 47 & $35.8-57.4$ & & \\
\hline$>2$ MTS sites & 30 & $18.3-40.8$ & 0.0007 & 0.025 \\
\hline $0-2$ MTS sites & 52 & $38.1-65.0$ & & \\
\hline Female & 26 & $11.6-40.4$ & 0.027 & 0.618 \\
\hline Male & 54 & $39.7-67.5$ & & \\
\hline$<65$ years & 38 & $30.1-46.2$ & $0.027 \mid$ & 0.343 \\
\hline$\geqslant 65$ years & 60 & $25.6-94.6$ & & \\
\hline Liver MTS & 25 & $22.7-27.0$ & 0.0186 & 0.574 \\
\hline No liver MTS & 47 & $36.8-56.6$ & & \\
\hline Lung MTS & 36 & $25.3-45.6$ & 0.0234 & 0.0804 \\
\hline No Lung MTS & 54 & $38.5-45.8$ & & \\
\hline No Bone MTS & 38 & $29.8-46.4$ & 0.0004 & 0.425 \\
\hline Bone MTS & 88 & $60.1-115$ & & \\
\hline Non-urologic tumours & 26 & $17.8-34.8$ & $<0.0001$ & 0.001 \\
\hline Urologic tumours & 98 & $67.6-129$ & & \\
\hline ECOG $0-1$ & 44 & $34.8-54.3$ & 0.0048 & 0.376 \\
\hline ECOG 2 & 17 & $12.6-22.8$ & & \\
\hline Monotherapy trial & 38 & $44.9-108$ & 0.0005 & 0.157 \\
\hline Combination trial & 76 & $28.4-47.8$ & & \\
\hline
\end{tabular}

Table 2 Trial responses and outcomes

'First in human'

\begin{tabular}{|c|c|c|c|c|}
\hline & Overall & Median (range) - n/N (\%) & Chemotherapy-based & $P$-value \\
\hline Number of Cycles & $2(1-17)$ & $2(1-17)$ & $4(1-17)$ & $<\mathbf{0 . 0 0 1}$ \\
\hline Treatment (weeks) & 7.7 & 6.9 & 10.6 & 0.027 \\
\hline Partial response & 19/202 (9.4) & $5 / 140(3.6)$ & 14/62 (22.6) & 0.001 \\
\hline CBR3 m (PR+SD > 3 months) & $73 / 202(36.1)$ & $36 / 140(25.7)$ & 37/62 (59.7) & 0.001 \\
\hline 30 days mortality rate & $4 / 212(1.9)$ & $2 / 148(1.3)$ & $2 / 64(3.1)$ & NS \\
\hline 90 days mortality rate & $39 / 212(18.3)$ & $28 / 148(18.9)$ & $11 / 64(17.2)$ & NS \\
\hline Toxicity-related mortality & $1 / 212(0.47)$ & $1 / 148(0.7)$ & $0 / 64(0)$ & NS \\
\hline
\end{tabular}

$\mathrm{CBR}_{3 \mathrm{~m}}=3$ months clinical benefit rate; NS = not significant; $\mathrm{PR}=$ partial response; $\mathrm{SD}=$ stable disease. $P$-values calculated by Mann-Withney's U-test, $\chi^{2}$ test and Fisher's F-test. 
portfolio included docetaxel regimens, we also assessed the outcome according to disease type; urologic $v s$ non-urologic cancer. Urologic cancers were associated with a significant better outcome compared to non-urologic cancers, $P=0.001$ (Table 3).

A risk score based on the results of the outcome of the MVA $\left(\mathrm{LDH}\right.$ normal $=0$ vs $\mathrm{LDH}>\mathrm{UNL}=1$, albumin $>35 \mathrm{gl}^{-1}=0$ vs $<35 \mathrm{gl}^{-1}=1$, site of metastasis $\left.<2=0 v s>2=1\right)$ demonstrated that patients with a score $<2$ had a significantly longer OS (74.1 vs 24.9 weeks, $P=0.0001)$. Moreover, the same score remained highly predictive for urological patients, a subgroup with a significant better OS, and could also distinguish between a good and poor prognosis cohort in this group of patients (Figure 2A, B and C).

\section{DISCUSSION}

The primary objectives of a phase I trial have classically been to determine the toxicity profile of a new drug therapy and its MTD. However, the clinical outcome measured in RR, PFS and OS is usually descriptive due to the small numbers of patients enrolled in these studies.

Previous retrospective analyses have studied the outcome for patients on phase I trials and have reported RRs between 3.8 and $17.8 \%$ with higher RR in patients who received classical cytotoxic drugs compared to patients who received biological agents (Sekine et al, 2002; Roberts et al, 2004; Horstmann et al, 2005). These studies however reviewed the outcome over a long period of time, sometimes more than 10 years, which may not reflect the current status of drug development. Moreover, these trials analysed only the published outcome of clinical trials rather than individual patient data.

In our patient group, with a broad spectrum of different cancers, the RR was $9.4 \%$ and median PFS and OS were 11 and 43 weeks, respectively, after a median follow-up of 34 weeks. Patients who received a chemotherapy-based regimen with or without a biological agent had significantly higher RR compared to patients who received non-cytotoxic agents (19.7 vs 3.6\%). These results are in keeping with the aforementioned published analysis comprising more than 460 phase I trials over a 12-year period, which found an $\mathrm{RR}$ of $17.8 \%$ for patients who received a chemotherapy-based regimen compared to $4.4 \%$ for patients who received noncytotoxic agents. No data were available on patients achieving $\mathrm{SD}$, nor was a survival analysis performed in that study (Horstmann et al, 2005).

A patient-specific analysis was performed in a single centre retrospective analysis, which enrolled 420 patients treated within 16 phase I trials over a 10 -year period. This study showed OS rates of 38 weeks for patients who received cytotoxic-based regimens compared to 27 weeks for patients who received non-cytotoxic treatment. These results were similar to our survival analysis, which showed that classical cytotoxic-based regimens resulted in longer OS compared to biological agents. This trial also confirmed that RR was significantly higher in patients receiving cytotoxic agents compared to patients who received non-cytotoxic agents (14.1 vs 1\%, $P<0.001$ ) (Han et al, 2003).

Our series demonstrated a better outcome for patients who had disease control (CBR: PR $+\mathrm{SD})$, which was reflected in an overall CBR of $36 \%$ at 3 months and $26 \%$ at 6 months, respectively. It is notoriously difficult to attribute a better outcome to treatment effect in a non-randomised study analysis where patient selection clearly is a major factor. However, the achievement of SD lasting more than 3 months in advanced cancer patients with previous disease progression is noteworthy, and in several cases has justified the further development of the agent under investigation.

The patients who died within the first 3 months of treatment reflected a group with an unfavourable prognosis. Our analysis showed that these patients had significantly higher LDH, WCC and lower albumin and haemoglobin levels compared to the rest of the
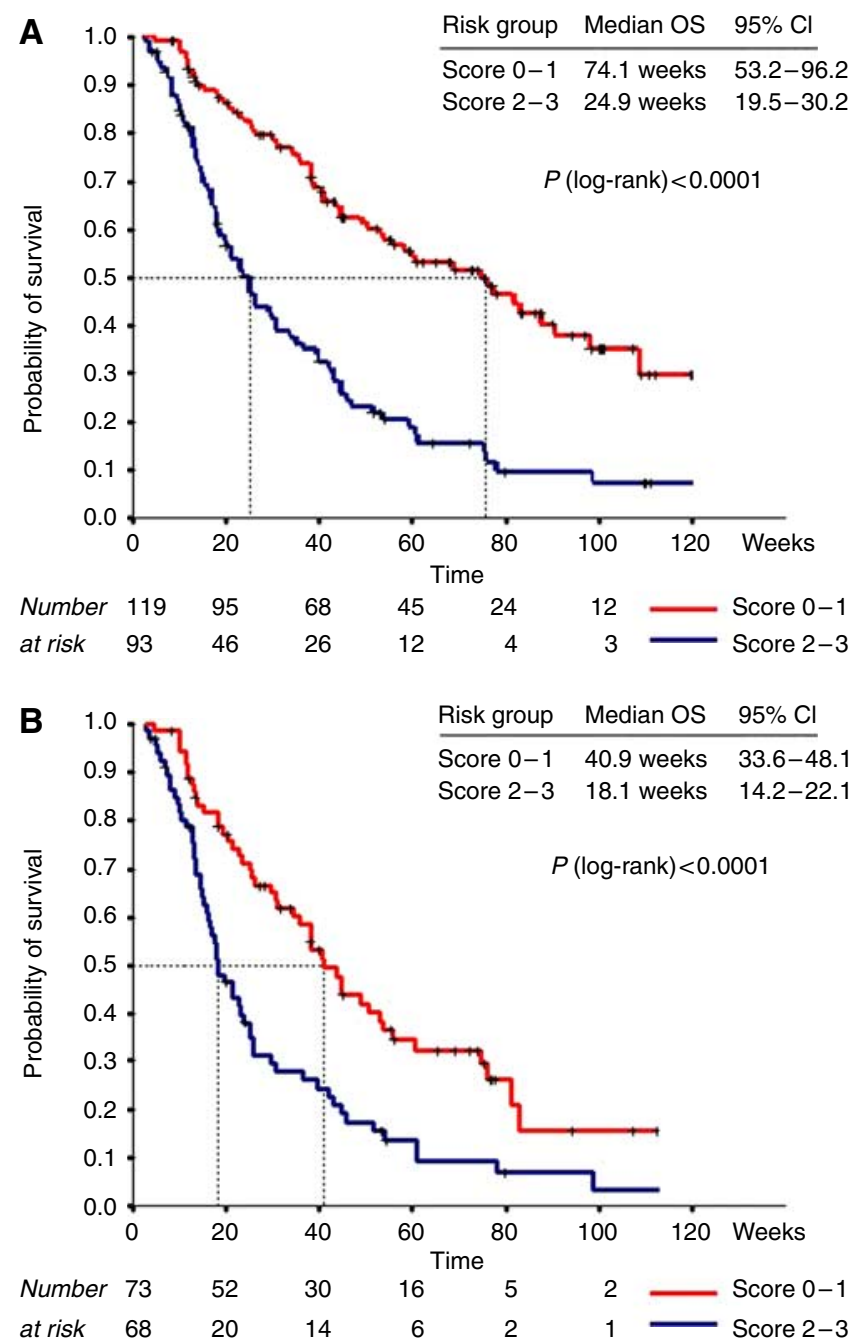

$\begin{array}{lllllll}\text { at risk } & 68 & 20 & 14 & 6 & 2 & 1 \text { - Score 2-3 }\end{array}$

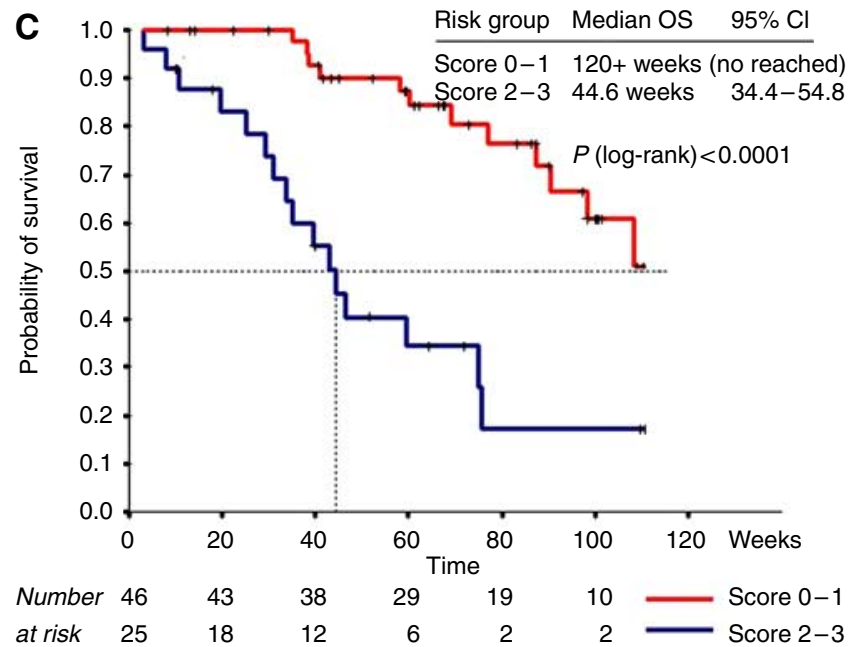

Figure 2 OS by risk categories. Kaplan-Meier curves for OS based on MVA risk score (albumin $<35 \mathrm{~g} \mathrm{I}^{-1}+1$; elevated $\mathrm{LDH}>\mathrm{UNL},+1 ;>2$ sites of metastasis, +1$)$. (A) Whole series $(n=212)$, score $0-1(n=119)$ and score $2-3(n=93)$. (B) Non-urological cancers $(n=141)$, score $0-1$ $(n=73)$ and score $2-3(n=68)$. (C) Urological tumours $(n=7 I)$, score $0-I(n=46)$ and score $2-3(n=25)$. 
population. Similar results were demonstrated in a study, which included 70 phase I patients. All patients who presented with the following two risk factors, albumin $<38 \mathrm{gl}^{-1}$ and lymphocyte count $<0.7 \times 10^{9} 1^{-1}$, died within 90 days (Penel et al, 2008). Another study, which analysed 154 patients over an 8-year period, identified two independent risk factors, namely LDH > 600 IU and PS $>1$, which were correlated with a shorter 90 -day OS for patients with both factors. The authors recommended that patients with these risk factors should not participate in a phase I trial (Bachelot et al, 2000). Interestingly, this study also revealed that patients $\geqslant 65$ years had a significantly better OS than younger patients in keeping with our findings. A possible explanation includes more aggressive tumour biology in younger patients.

In our MVA, parameters such as $\mathrm{LDH}>\mathrm{UNL}$, albumin $<35 \mathrm{gl}^{-1}$, sites of metastasis $>2$ have been associated with a significantly poorer clinical outcome. On the basis of these results, a prognostic score model was developed (LDH normal (0) vs $\mathrm{LDH}>\mathrm{UNL}(+1)$, albumin $>35 \mathrm{gl}^{-1}$ (0) vs albumin $<35 \mathrm{gl}^{-1}$ $(+1)$, site of metastasis $<2(0) v s>2(+1))$. Our prognostic score demonstrated that patient with a good risk score $(0$ and 1

\section{REFERENCES}

Bachelot T, Ray-Coquard I, Catimel G, Ardiet C, Guastalla JP, Dumortier A, Chauvin F, Droz JP, Philip T, Clavel M (2000) Multivariable analysis of prognostic factors for toxicity and survival for patients enrolled in phase-I clinical trials. Ann Oncol 11: 151-156

Bubley GJ, Carducci M, Dahut W, Dawson N, Daliani D, Eisenberger M, Figg WD, Freidlin B, Halabi S, Hudes G, Hussain M, Kaplan R, Myers C, Oh W, Petrylak DP, Reed E, Roth B, Sartor O, Scher H, Simons J, Sinibaldi V, Small EJ, Smith MR, Trump DL, Vollmer R, Wilding G (1999) Eligibility and response guidelines for phase II clinical trials in androgen-independent prostate cancer: recommendations from the Prostate-Specific Antigen Working Group. J Clin Oncol 17: $3461-3467$

Cox DR (1972) Regression models and life tables. J Roy Stat Soc (B) 34: $187-202$

Han C, Braybrooke J P, Deplanque G, Taylor M, Mackintosh D, Kaur K, Samouri K, Ganesan TS, Harris AL, Talbot DC (2003) Comparison of prognostic factors in patients in phase I trials of cytotoxic drugs $v s$ new noncytotoxic agents. $B r$ J Cancer 89: $1166-1171$

Horstmann E, McCabe MS, Grochow L, Yamamoto S, Rubinstein L, Budd T, Shoemaker D, Emanuel EJ, Grady C (2005) Risks and benefits of phase-1 oncology trials, 1991 through 2002. N Engl J Med 352: 895-904 risk factors) had significantly superior OS compared to patients with a poor risk score ( $>2$ risk factors). This score has been also proved to be valid in the subgroup of urological cancer patients. The use of this score might be helpful for the future as it is based solely on objective clinical parameters. It could be a helpful tool in evaluating the eligibility of patients into phase I trials. We are currently performing a prospective analysis in our phase I patients to validate this scoring system.

This analysis demonstrated that treatment within the context of a phase I trial could be considered as a valuable therapeutic option. Interestingly, those trials incorporating classical cytotoxics were associated with a better outcome. Clearly, this relates to patient selection, particularly when the trial may involve the use of a cytotoxic in chemonaive cases. The treatment in our cohort was generally well tolerated and treatment-related deaths and toxicities were low. Moreover, a significant number of patients achieved disease control for a significant duration. However, the challenge remains in appropriate patient selection and for this, the use of an objective clinical score could be a helpful tool.

Kaplan EL, Meier P (1958) Nonparametric estimation from incomplete observations. J Am Stat Ass 53: 457-481

Penel N, Vanseymortier M, Bonneterre ME, Clisant S, Dansin E, Vendel Y, Beuscart R, Bonneterre J (2008) Prognostic factors among cancer patients with good performance status screened for phase I trials. Invest New Drugs 98(1): $53-58$

Roberts TG, Goulart BH, Squitieri L, Stallings SC, Halpern EF, Chabner BA, Gazelle GS, Finkelstein SN, Clark JW (2004) Trends in the risk and benefits to patients with cancer participating in phase-I clinical trials. JAMA 292: $2130-2140$

Sekine I, Yamamoto N, Kunitoh H, Ohe Y, Tamura T, Kodama T, Saijo N (2002) Relationship between objective responses in phase-I trials and potential efficacy of non-specific cytotoxic investigational new drugs. Ann Oncol 13: $1300-1306$

Therasse P, Arbruck SG, Eisenhauer EA, Wanders J, Kaplan RS, Rubinstein L, Verweij J, Van Glabbeke M, van Oosterom AT, Christian MC, Gwyther SG (2000) New guidelines to evaluate the response to treatment in solid tumors. J Natl Cancer Inst 92: 205-216

Yamamoto N, Tamura T, Fukuoka M, Saijo N (1999) Survival and prognostic factors in lung cancer patients treated in phase-I trials: Japanese experience. Int J Oncol 15: 737-741 